\title{
Acid leaching and kinetics study of cobalt recovery from spent lithium-ion batteries with nitric acid
}

\author{
Yuliusman $^{1, *}$, Radifan Fajaryanto ${ }^{1}$, Annisaa Nurqomariah $^{1}$, and Silvia ${ }^{1}$ \\ ${ }^{1}$ Department of Chemical Engineering, Faculty of Engineering, Universitas Indonesia, Depok 16424, Indonesia
}

\begin{abstract}
Relentless development of technology triggers the smartphone production. The increasing number of smartphone use is followed by escalation of its waste, where its battery is usually left unrecycled. The analysis of the battery content shows that it is consist of a considerable amount of cobalt that can be reutilized based on its relatively high economic value, which valued USD $61 / \mathrm{kg}$. Leaching as a form of hydrometallurgy was used in this research to recover cobalt using $\mathrm{HNO}_{3}$ as leaching agent and $\mathrm{H}_{2} \mathrm{O}_{2}$ as reducing agent. Process optimization was done by varying concentration of nitric acid and reaction temperature. The result showed that the optimum leaching condition was earned in 30 minutes of leaching reaction using $3.0 \mathrm{M} \mathrm{HNO}_{3}$ at the reaction temperature of $90{ }^{\circ} \mathrm{C}$, resulting $98.01 \%$ of cobalt leaching efficiency. Reaction kinetics study was also done in this research and the result demonstrates that recovery of cobalt from spent lithium-ion battery by nitric acid leaching was controlled by diffusion through product layer with activation energy value of $44.67 \mathrm{~kJ} / \mathrm{mol}$.
\end{abstract}

\section{Introduction}

According to Survei Penduduk Antar Sensus (SUPAS) which is done by Badan Pusat Statistik (BPS) in 2015, the population of Indonesia is about 255.18 million people [1]. In 2017, the Indonesian smartphone users is projected to $39.8 \%$ of the total population or about 101.56 million of people [2]. This phenomenon challenges smartphone providers to innovate and develop smartphone product, including its battery as one of the most important features. Lithium-ion battery is often used as smartphone battery due to its characteristics: lightweight, high energy density, rechargeability, and low maintenance [3].

Besides all the advantages, there are also side effects available that is harmful for the users and environment. The greater the smartphone users, the more lithium-ion batteries produced and automatically increase the amount of lithium-ion battery waste. Lithium-ion battery naturally can only sustain in 2-3 years of lifetime, then it immediately becomes a pollutant to its environment as a toxic and hazardous waste. Therefore, lithium-ion battery is needed to be specially treated $[4,5,6]$.

Lithium-ion batteries contain heavy metals, organic chemical compounds, and plastics. In the analysis of the substance content of lithium-ion batteries, it was found that there was a heavy metal content, organic chemicals, and plastics with a composition of 5-20\% cobalt, 5-10\% nickel, $5-7 \%$ lithium, $15 \%$ organic chemicals, and $7 \%$ of the plastic, in which the composition depends on the battery maker [3]. From the composition, it can be seen there are sufficient amount of cobalt metal that can still be utilized. The potential of this reusable metal cobalt is due to the high economic value of the cobalt metal, which is USD $61 / \mathrm{kg}$ or approximately IDR $825,208 / \mathrm{kg}$ at an exchange rate of USD 1 equivalent to IDR 13,528 per November 10, 2017. In addition, cobalt is not only classified as precious metals, but also classified as harmful and toxic metals to the environment. Therefore, the recovery of cobalt metal becomes an important thing to examine.

The recycling process as a special treatment for recovering cobalt metal from waste batteries has been widely reviewed and studied. Much of the process proposed in the processing of waste lithium-ion batteries is through hydrometallurgical chemistry and has been developed on a laboratory scale, with the aim of recovering precious metals from its cathode [7]. The hydrometallurgical chemical process commonly used in waste treatment to recover a metal is leaching.

In its definition, leaching is a method for dissolving a soluble substance from within a mixture of insoluble solids [8]. The solvent in the leaching process is called the leaching agent, where the leaching agent in the leaching process of the metal is usually an acid. The acids used in the metallic leaching process are mostly strong acid groups, such as sulfuric acid $\left(\mathrm{H}_{2} \mathrm{SO}_{4}\right)$, hydrochloric acid $(\mathrm{HCl})$, and nitric acid $\left(\mathrm{HNO}_{3}\right)$ [9]. To improve leaching efficiency, a study was developed on the addition of reducing agents. In a previous study conducted in South Korea [9], the recovery of cobalt metal reached $95 \%$ using nitric acid with a concentration of $1 \mathrm{M} \mathrm{HNO}_{3}$ and 1.7 vol\% $\mathrm{H}_{2} \mathrm{O}_{2}$. Over the past several years, $\mathrm{HNO}_{3}$ leaching technique is rarely used to recover

Corresponding author: usman@,che.ui.ac.id 
valuable metals from waste of electrical and electronic equipments (WEEE) [10], especially in Indonesia. Therefore, this research is done to develop the previous research especially for smartphone's lithium ion battery cobalt recovery in Indonesia.

\section{Research Methodology}

\subsection{Preparation of spent lithium-ion batteries}

Spent lithium-ion batteries were earned collectively from smartphone service market. The batteries were then soaked into a $1 \mathrm{wt} \%$ sodium chloride solution for about 24 hours to discharge the remaining charge to reduce potentially hazardous risks. Batteries were then dismantled to parts and the cathode was manually dredged to remove the $\mathrm{LiCoO}_{2}$ part from the aluminum foil. The $\mathrm{LiCoO}_{2}$ part was then grounded to form fine powder and then sieved into a mesh no. 100 sieve to ensure the powder was formed uniformly. Cobalt content in the $\mathrm{LiCoO}_{2}$ was then analyzed using AAS instrument.

\subsection{Leaching process}

Nitric acid solution as leaching agent was prepared from a $60 \%$ nitric acid reagent in addition to $1.7 \mathrm{vol} \%$ hydrogen peroxide from $35 \%$ hydrogen peroxide reagent to distilled water. The leaching process was carried out in a $100 \mathrm{ml}$ Erlenmeyer flask with $20 \mathrm{~g} / \mathrm{L}$ solid/liquid ratio and stirred at $400 \mathrm{rpm}$ on a hotplate magnetic stirrer and equipped with a thermometer to ensure the correct value of temperature applied in the leaching process. To obtain optimum conditions, the nitric acid concentration and reaction temperature was done at various condition. Cobalt content in the leach liquor was then analyzed using AAS instrument.

\section{Results and Discussion}

\subsection{Effect of leaching agent concentration}

Fig. 1 demonstrates the effect of leaching agent concentration variation $(0.5 \mathrm{M}, 1.0 \mathrm{M}, 1.5 \mathrm{M}, 2.0 \mathrm{M} ., 3.0$ $\mathrm{M}$, and $4.0 \mathrm{M}$ ). Trend in Fig. 1 shows that at concentrations of $0.5 \mathrm{M}$ to $1.0 \mathrm{M}$ nitric acid, there is a significant increase. This is in accordance with the previous research [9], where there is an increasing trend of the lithium-ion battery cathode waste leaching to a concentration of $1.0 \mathrm{M}$. Furthermore, the study continued to reach a concentration of $2.0 \mathrm{M}$ and still could not find the optimum point of leaching. After continuing up to a concentration of $4.0 \mathrm{M}$, it is known that the optimum point of the lithium-ion battery cathode waste leaching with the previously mentioned independent variables is in the concentration of nitric acid of $3.0 \mathrm{M}$, which is equal to $71.26 \%$. The continuation of increasing leaching efficiency does not show significant changes after the optimum condition is reached when using strong acid as leaching agent [11].
In principle, lithium-ion battery cathode leaching process partially decomposes the $\mathrm{LiCoO}_{2}$ compound

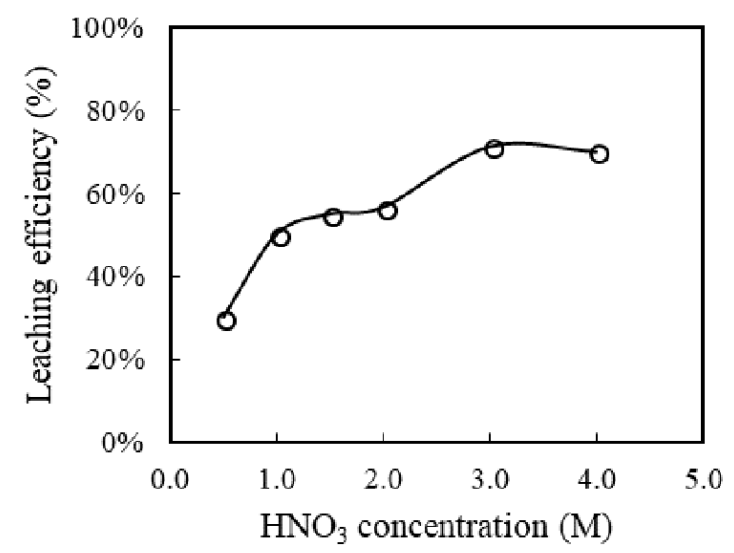

Fig. 1. Effect of leaching agent concentration

until the metal elements contained therein are dissolved in the leaching solution. The reaction that occurs between nitric acid and $\mathrm{LiCoO}_{2}$ compounds consists of three stages, namely reactant layer diffusion, surface reaction, and product layer [12]. Initially, the nitric acid leaching agent diffuses onto the surface of the $\mathrm{LiCoO}_{2}$ compound, then the nitric acid reacts with the cobalt metal elements by the adsorption and chemical reaction process and ends with a product of cobalt (II) nitrate leaving the liquid-solid interface and dissolved into the acid nitrate through the diffusion process. Because the $\mathrm{LiCoO}_{2}$ bonds is too strong, reducing agent in the form of $\mathrm{H}_{2} \mathrm{O}_{2}$ influences the $\mathrm{Co}^{3+}$ ion to $\mathrm{Co}^{2+}$. This results in the increasing leaching efficiency of the cobalt metal, because the $\mathrm{Co}^{2+}$ ion is more easily dissolved and reacts with acids than the $\mathrm{Co}^{3+}$ ion [9], where there is the formation of cobalt (II) nitrate or $\mathrm{Co}\left(\mathrm{NO}_{3}\right)_{2}$. Microscopically, previous research has shown that leaching efficiency of the metal is greatly influenced by leaching agent concentration, where greater leaching agent concentration will increase its efficiency. The increasing leaching efficiency then will not show significant change after the optimum condition is reached when using strong acid as leaching agent [11].

\subsection{Effect of reaction temperature}

One of the most influential parameters of the leaching process is the operating temperature. In a previous study, it was shown that by using $\mathrm{H}_{2} \mathrm{SO}_{4}$ as leaching agent for leaching time about 2 hours at $20{ }^{\circ} \mathrm{C}$, leaching efficiency of cobalt metal showed a value of $70 \%$. At $60{ }^{\circ} \mathrm{C}$, leaching efficiency of cobalt metal was $95.88 \%$, while for above $60{ }^{\circ} \mathrm{C}$ the increase was not significant [11]. To prove that leaching operation temperature also influences leaching process by using leaching agent $\mathrm{HNO}_{3}$, this research also discovers the effect of leaching operation temperature to leaching efficiency of cobalt metal. The operating temperature of leaching is varied at $60{ }^{\circ} \mathrm{C}, 70$ ${ }^{\circ} \mathrm{C}, 80{ }^{\circ} \mathrm{C}, 90{ }^{\circ} \mathrm{C}$. 
The trend of increasing efficiency in Fig. 2. shows that leaching efficiency of cobalt metal is influenced by the temperature of leaching operations, where the greater

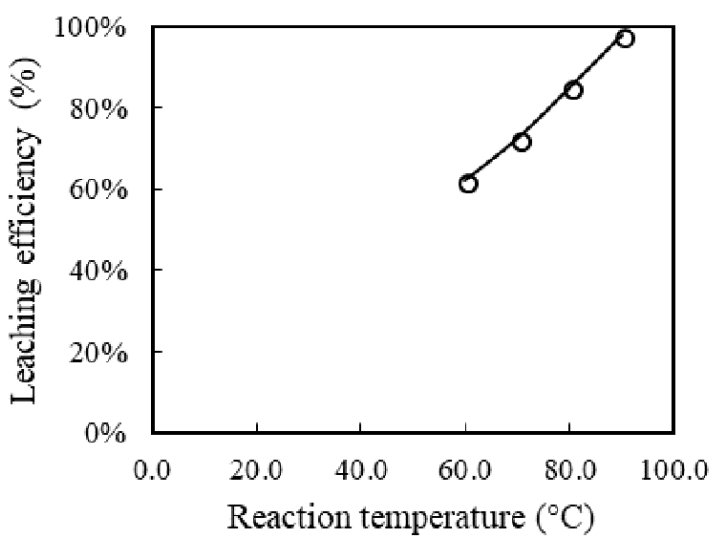

Fig. 2. Effect of reaction temperature

the operating temperature, the leaching efficiency of cobalt metal is also greater. Microscopically, this is caused by intermolecular collisions that move faster at high temperatures. This is defined by the Arrhenius equation as follows [13].

$$
K=A \exp \left(-E_{a} / R T\right)
$$

$\mathrm{K}$ is the rate constant, $\mathrm{A}$ is the collision frequency, $\mathrm{E}_{\mathrm{a}}$ is the activation energy, $\mathrm{R}$ is the universal gas constant, and $\mathrm{T}$ is the absolute temperature. Activation energy is the minimum energy required for the occurrence of a collision. The rate of product formation reaction is influenced by the amount of energy, where the greater the amount of energy compared to the activation energy, the number of products formed will also be greater. The temperature must be high enough to make the energy generated far greater than the activation energy, resulting in more intermolecular collisions and increasing the rate of product formation reactions.

\subsection{Reaction kinetic study}

To find out how the reaction phenomenon between nitric acid and $\mathrm{LiCoO}_{2}$ compounds, the reaction kinetics study was conducted with the objective of determining the reaction rate controller and activation energy required in the leaching process of the lithium-ion battery cathode to recover the cobalt metal using nitric acid. By using the optimum leaching agent concentration obtained in the previous stage of $3.0 \mathrm{M}$, the research is then done to study the comparison of reaction time effect to cobalt leaching efficiency for temperature of $60{ }^{\circ} \mathrm{C}, 70{ }^{\circ} \mathrm{C}, 80$ ${ }^{\circ} \mathrm{C}$, and $90{ }^{\circ} \mathrm{C}$.

Fig. 3. shows a comparison of leaching time effect profiles to cobalt leaching efficiency at $60^{\circ} \mathrm{C}, 70{ }^{\circ} \mathrm{C}, 80$ ${ }^{\circ} \mathrm{C}$, and $90{ }^{\circ} \mathrm{C}$ as the basis for reaction kinetics studies. The operating temperature applied in the reaction kinetics study is of equal value to the operating temperature variations in the previous stage and the length of leaching time in the reaction kinetics phase is also adjusted to the time of the leaching reaction at the previous stage. Based on Fig. 3., it can be seen the longer leaching time, the efficiency of leaching is also greater. This also applies to large operating temperatures

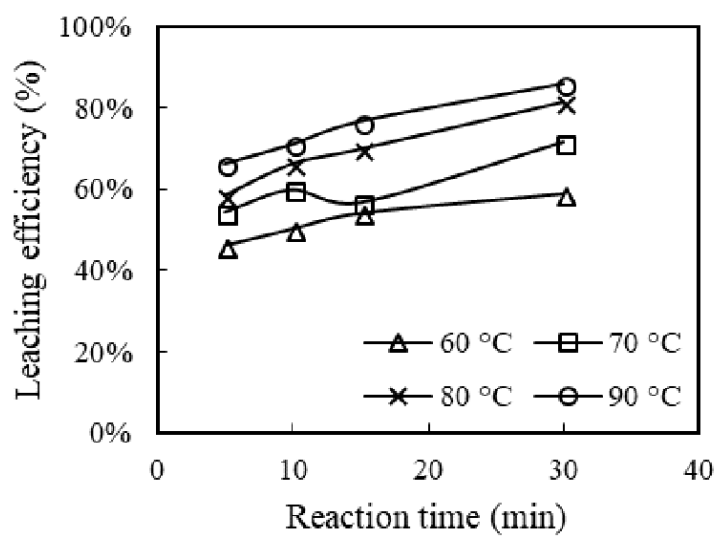

Fig. 3. Comparison of effect of reaction time for various temperature

temperatures, where the greater the operating temperature applied the higher the cobalt leaching efficiency.

In a kinetics study of leaching reactions of lithiumion battery cathode batteries by nitric acid, a heterogeneous model reaction approach [14] was used. This heterogeneous reaction model makes it possible to assume a liquid-solid heterogeneous reaction condition in which the $\mathrm{LiCoO}_{2}$ cathode solid is assumed to be a spherical non-porous solid covered by a thin layer of leaching agent fluid. Right between the outer surface of the $\mathrm{LiCoO}_{2}$ cathode solid and the thin layer of leaching agent fluid, mass transfer occurs between the solids with the leaching agent liquid. The heterogeneous reaction model that occurs in this reaction is known as the Shrinking Core Model, which is a model that describes a situation in which solid particles are consumed by dissolution or reaction resulting in a product, thereby reducing the amounts of solids and shrinkage of the solid material.

In a liquid-solid reaction system, the reaction rate is usually controlled by diffusion through the surface of the product or chemical reaction at the surface of the material [15]. If the reaction is controlled by a chemical reaction on the surface, the reaction rate control equation is defined as [16]:

$$
1-(1-X)^{1 / 3}=K_{r} t
$$

If the reaction is controlled by diffusion through the product surface, the reaction rate control equation is defined as [16]:

$$
1-(2 / 3) X-(1-X)^{2 / 3}=K_{d} t
$$

where $\mathrm{X}$ is the reacting fraction, $\mathrm{K}_{\mathrm{r}}$ is the kinetic parameter for the surface reaction control, $K_{d}$ is the kinetic parameter for the control of the product diffusion, and $t$ is the reaction time in minutes.

Percentage efficiency of cobalt leaching is then plotted on the chart using equations 2 and 3 with the aim of determining the reaction control of the leaching 
process. The determination of the reaction control is evaluated from the linearity of the line formed from the percentage data plot of cobalt leaching efficiency. The parameter determining the linearity of the line is the value of $\mathrm{R}^{2}$ of the line formed. The larger the value of $\mathrm{R}^{2}$, the line is increasingly linear. The linearity of the two equations is then compared and the controller is determined from a linearly more suitable line to the reaction kinetics model than the other line based on the value of $R^{2}$.

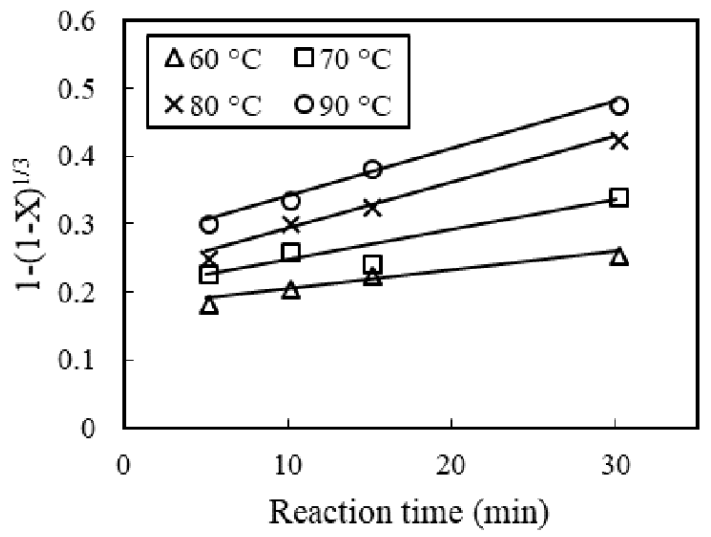

Fig. 4. Plot of leaching with surface reaction model

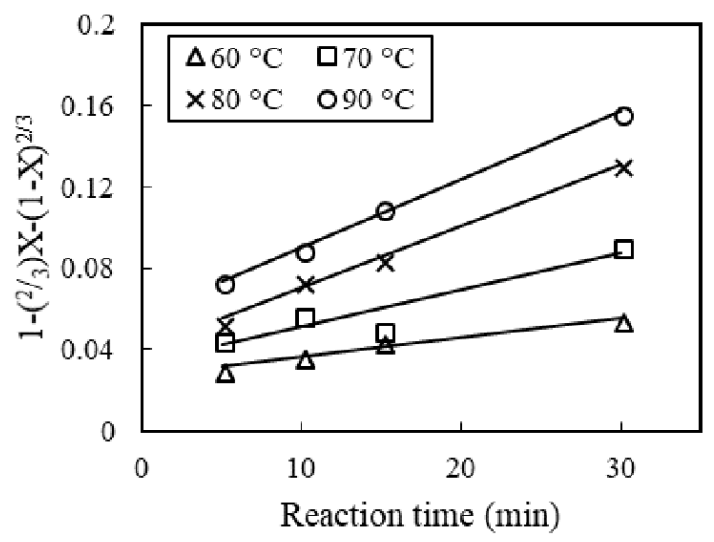

Fig. 5. Plot of leaching with diffusion reaction model

Table 1. $\mathrm{R}^{2}$ value of kinetics model

\begin{tabular}{ccc}
\hline $\begin{array}{c}\text { Temperature } \\
\left({ }^{\circ} \mathrm{C}\right)\end{array}$ & $\begin{array}{c}c \\
\mathrm{R}^{2} \text { value } \\
\text { reaction }\end{array}$ & Diffusion \\
\hline 60 & 0.9494 & 0.9627 \\
70 & 0.8725 & 0.8745 \\
80 & 0.9916 & 0.9956 \\
90 & 0.9953 & 0.9971 \\
\hline
\end{tabular}

Fig. 4. shows trend for cobalt leaching profile with kinetics model of surface chemical reaction, while Fig. 5. shows the trend for the diffusion reaction kinetic model. By comparing the overall linearity of the line, the diffusion reaction kinetic model has a higher level of linearity than the surface chemical reaction kinetics model for cobalt leaching with leaching agent of nitric acid. Thus, it is predicted that an appropriate reaction model for the cobalt leaching study with nitric acid leaching agent is the kinetic model of the diffusion reaction. To prove that the model prediction is correct, the analysis of activation energy is also done.

The value of the activation energy can be determined by using the modified Arrhenius equation as follows [17].

$$
\ln k=\left(-E_{a} / R\right) \cdot(1 / T)+\ln A
$$

In the previous stage, it has been found that the reaction is controlled by diffusion through the surface of the product, then the value of $\mathrm{K}$ used is the value of $\mathrm{K}_{\mathrm{d}}$. Then, in accordance with equation 4, the activation energy can be known by multiplying the gradient value of the line equation with the universal gas constant value. The line equation can be formed by plotting $1 / T$ data on $\ln \left(\mathrm{K}_{\mathrm{d}}\right)$. Fig. 6. explains the relationship between the value of $1 / \mathrm{T}$ with $\ln \left(\mathrm{K}_{\mathrm{d}}\right)$.

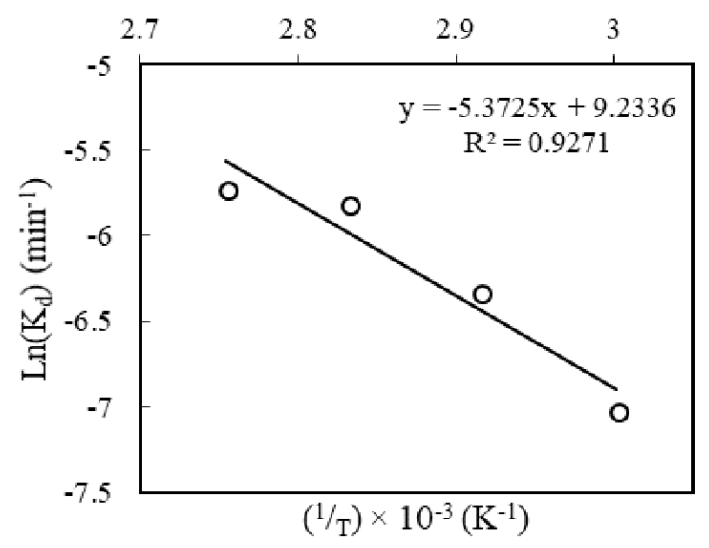

Fig. 6. Arrhenius equation plot for nitric acid leaching

Based on Fig. 5., the equation forms the line with a gradient value of -5.3725 . The value of the activation energy of the diffusion reaction through the product surface can be calculated by multiplying the value of the gradient with the universal gas constant value in $\mathrm{kJ} / \mathrm{K} \cdot \mathrm{mol}$ units. The activation energy of calculations for leaching of cobalt metal is $44.67 \mathrm{~kJ} / \mathrm{mol}$ or equivalent to $10.68 \mathrm{kcal} / \mathrm{mol}$.

\section{Conclusions}

Based on the research result, leaching efficiency increased until an optimum point of nitric acid concentration is reached, that is $3.0 \mathrm{M}$. The optimum point of reaction temperature is reached at $90{ }^{\circ} \mathrm{C}$. The reaction kinetic study shows that cobalt leaching with nitric acid leaching agent is controlled by diffusion reaction with activation energy of $44.67 \mathrm{~kJ} / \mathrm{mol}$ or equivalent to $10.68 \mathrm{kcal} / \mathrm{mol}$. 
This research is supported by Hibah Publikasi Internasional Terindeks untuk Tugas Akhir Mahasiswa UI (PITTA) 2018 from universitas Indonesia.

\section{References}

[1] Badan Pusat Statistik. Profil Penduduk Indonesia Hasil SUPAS 2015. Jakarta: Badan Pusat Statistik. (2016)

[2] eMarketer. Smartphone Penetration Doubles in Indonesia. (2013) [Online]

Available at:

https://www.emarketer.com/Article/Smartphone-

Penetration-Doubles-Indonesia/1010102 [Accessed 24 October 2017].

[3] Shin, S. M. et al., Hydrometallurgy. 79(3-4), pp. 172-181. (2005)

[4] Castillo, S., Ansart, F., Laberty-Robert, C. \& Portal, J., J. Power Sources. 112(1), pp. 247-254. (2002)

[5] Contestabile, M., Panero, S. \& Scrosati, B., J. Power Sources, 83(1-2), pp. 75-78. (1999)

[6] Lain, M. J., J. Power Sources, Volume 97-98, pp. 736-738. (2001)

[7] Li, L., Chen, R., Sun, F. \& Liu, J., Hydrometallurgy, 108(3-4), pp. 220-225. (2011)

[8] McCabe, W. L., Smith, J. C. \& Harriott, P., Unit Operations of Chemical Engineering. 7th ed. Singapore: McGraw-Hill. (2005)

[9] Lee, C. K. \& Rhee, K.-I., Hydrometallurgy, 68(13), pp. 5-10. (2003)

[10] Bas, A. D., Deveci, H., \& Yazici, E. Y., Sep. Purif. Technol., Volume 130, pp. 151-159. (2014)

[11] Zhu, S.-g.et al., Transaction of Nonferrous Metals Society of China, 22(9), pp. 2274-2281. (2012)

[12] Nurasad, W., Perolehan Kembali Logam Li dari Limbah Baterai Li-ion dengan Teknologi Membran Cair Emulsi Menggunakan Cyanex 921 Sebagai Ekstraktan, Depok: Universitas Indonesia. (2016)

[13] Levenspiel, Chemical Reaction Engineering, Singapore: John Wiley \& Sons. (1999)

[14] He, S., Wang, J. \& Yan, J., Hydrometallurgy, 108(3-4), pp. 171-176. (2011)

[15] Wang, X. et al., Sep. Purif. Technol., Volume 115, pp. 66-72. (2013)

[16] Meshram, P. et al., Jom-J Min Met Mat S, Volume 68(10), pp. 2613-2623. (2016)

[17] Amiliana, R. A., Perolehan Kembali Logam Seng (Zn) dan Mangan (Mn) dari Limbah Baterai Zn-C dan Alkalin Bermetode Leaching dengan Reagen Asam Organik, Depok: Universitas Indonesia. (2017) 